\title{
Device Subject Relationships Supplemental Qualifiers Dataset
}

National Cancer Institute

\section{Source}

National Cancer Institute. Device Subject Relationships Supplemental Qualifiers Dataset. NCl Thesaurus. Code C147202.

A dataset containing supplemental information, specifically non-standard variables, to parent records in the device subject relationships domain. 